ORIGINAL ARTICLE

\title{
Nail gun injuries in residential carpentry: lessons from active injury surveillance
}

\author{
H J Lipscomb, J M Dement, J Nolan, D Patterson, L Li
}

Injury Prevention 2003;9:20-24

See end of article for authors' affiliations

Correspondence to: Dr Hester J Lipscomb, Division of Occupational and Environmental

Medicine, Department of Community and Family Medicine, Box 3834, Duke University Medical Center, Durham, NC 27710, USA; hester.lipscomb@duke.edu

\begin{abstract}
Objective: To describe circumstances surrounding injuries involving nail guns among carpenters, calculate injury rates, identify high risk groups and preventive measures.

Methods and setting: Active injury surveillance was used to identify causes of injury among a large cohort of union residential and drywall carpenters. Injured carpenters were interviewed by experienced journeymen; enumeration of workers and hourworked were provided by the union. The combined data allowed definition of a cohort of carpenters, their hours worked, detailed information on the circumstances surrounding injuries, and identification of preventive measures from the perspectives of the injured worker and an experienced investigator.

Results: Nail guns were involved in 14\% of injuries investigated. Ninety percent of these injuries were the result of the carpenter being struck, most commonly by a nail puncturing a hand or fingers. The injury rate among apprentices was 3.7 per 200000 hours worked (95\% confidence interval (Cl) 2.7 to 4.9$)$ compared with a rate of 1.2 among journeymen $(95 \% \mathrm{Cl} 0.80$ to 1.7$)$. While not always the sole contributing factor, a sequential trigger would have likely prevented $65 \%$ of the injuries from tools with contact trip triggers.

Conclusions: Training, engineering, and policy changes in the workplace and manufacturing arena are all appropriate targets for prevention of these injuries. Use of sequential triggers would likely decrease acute injury rates markedly. Over $70 \%$ of injuries among residential carpenters were associated with through nailing tasks (such as nailing studs or blocks, trusses or joists) or toe nailing (angled, corner nailing) as opposed to flat nailing used for sheathing activities; this provides some indication that contact trip tools could be used solely for flat nailing.
\end{abstract}

$\mathrm{P}$ neumatic nail guns are common tools in residential construction. The tools allow increased productivity, but also create injury risks. They are typically energized by air pressure supplied by a compressor, requiring a hose from the compressor to the gun. Similar tools are energized by carbon dioxide cylinders or they can be charge activated; the latter being used less often in residential construction. The tools are loaded with magazines of nails joined together. Framing nailers are capable of driving 3.5 inch nails into dense wood in less than a 10th of a second (fig 1). Common triggering mechanisms on these tools include contact trip and sequential triggers. The more common contact trip design allows nails to be discharged from the tool anytime the nose and the trigger mechanism are both depressed. Workers are able to hold the trigger down and do rapid fire "bounce" nailing to speed up production. The sequential design requires that the nose be depressed before the trigger in order to discharge a nail, making it more difficult to unintentionally discharge nails.

Much of the literature on nail gun injuries comes from case reports or series in trauma journals. ${ }^{1-5}$ Recent analyses of compensation claims in the State of Washington estimated rates of nail gun injuries in wood frame construction to be 2.06 per 200000 hours worked.$^{67}$ The injuries for these analyses were identified from coded data, lacking details on the circumstances surrounding the injuries. Puncture wounds to the hands and fingers are commonly reported, although there are reports of more serious, even fatal, injuries involving the face, eyes, and vital organs..$^{8-10}$

We report on nail gun injuries among a large cohort of union residential carpenters identified through active injury surveillance that included documentation and description of circumstances surrounding injuries from these tools, calculation of injury rates, and identification of high risk groups and preventive measures.

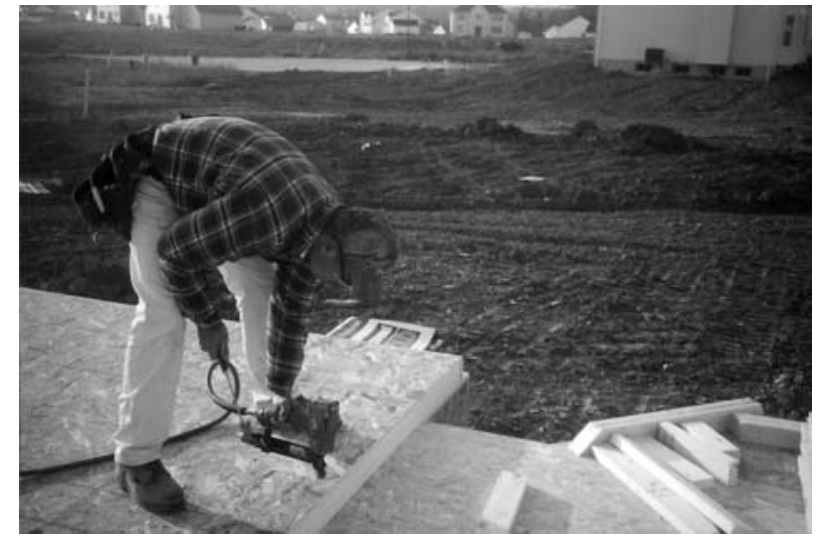

Figure 1 Contact trip stapler gun.

\section{METHODS}

Data for this report came from 37 months (September 1999 through September 2002) of active injury surveillance conducted in the area surrounding St Louis, Missouri; this is the only area of the United States with a large unionized workforce of residential carpenters. The work was done through partnership with the Carpenters' District Council of Greater St Louis and the Homebuilders Association of Greater St Louis. Residential and drywall contractors agreed to report

Abbreviations: $\mathrm{Cl}$, confidence intervals; FACE, Fatality Assessment Control and Evaluation (program); OSHA, Occupational Safety and Health Administration 
Occupational Safety and Health Administration (OSHA) recordable injuries (requiring medical care above first aid, loss of consciousness, or loss of work time beyond the day of injury) to the project office by facsimile or phone as they occurred on their work sites.

The surveillance approach was modeled after the National Institute for Occupational Safety and Health Fatality Assessment Control and Evaluation (FACE) program. In contrast to FACE, the primary focus was the bulk of work related injuries that do not result in death. Injured carpenters were interviewed by one of two experienced journeymen. These men had, respectively, 42 and 25 years of carpentry experience and safety training specific to the construction industry (OSHA 500). They were trained in procedures to obtain informed consent and the administration of a standard questionnaire for investigation of these injuries.

The questionnaire was developed with a steering committee, established early in the project, with representation from the union, contractors, contractors' safety personnel, and the academic research team. Questions were included about the nature and circumstances surrounding the injury, tools and materials being used, the stage of construction, time in the union, age, gender, safety training, weather conditions, stand-by exposures, and work of other trades on site. The carpenters were asked what caused or contributed to their injury. Interviews were conducted by phone. The investigating carpenter reported his own assessment of contributing factors and preventive recommendations in addition to those offered by the injured carpenter. The tool was pre-tested in the field over three months, including 46 investigations, with review and discussion of findings by the carpenter interviewers and the research team.

Union carpenters receive health and retirement benefits through trusteed health and welfare funds. Contractors hiring union labor pay into the trust based on the hours worked by the carpenters they hire. The local trust provided us with the hours worked per carpenter by contractor for each month, allowing us to calculate time at risk.

To supplement these data, a consecutive group of apprentices from the Carpenters Joint Apprenticeship Committee in St Louis were asked to complete a short questionnaire on their experiences with nail guns, injuries experienced, and training.

\section{Analyses}

Descriptive statistics were generated from the surveillance interviews and the apprentice questionnaire. Distributions of age, gender, and union status (apprentice $v$ journeymen) of the dynamic cohort were calculated. All nail gun and staple injuries were identified from responses to questions in the interview about tool use at time of injury. Text descriptions from the surveillance data were reviewed to confirm that the injury involved one of these tools. Injuries were described by the nature, body region, and mechanism based on the report of the carpenter. The proportion of cases resulting in lost time, beyond the day of injury, was also calculated.

Text descriptions were used to identify more common patterns and circumstances of injury. A series of queries and cross tabulations assisted in this process. Text descriptions and recommendations were reviewed and coded for additional concepts of interest including type of tool, type of nailing (flat surface, toenailing, through nailing), double fires, ricochets, projectile nails, and penetrations

The sum of hours worked by the cohort during the 37 months was calculated; hours worked were stratified by union status. Crude and stratified injury rates were calculated per 200000 hours worked (100 person-years of full time work) limited to data from injured carpenters who participated in the interview. Confidence intervals (CI) were calculated as described by Haenszel et al, assuming a Poisson distribution. ${ }^{11}$ All analyses were done through Microsoft ACCESS queries and export of data to SAS. ${ }^{12}{ }^{13}$

\begin{tabular}{|c|c|}
\hline \multicolumn{2}{|c|}{$\begin{array}{l}\text { Table } 1 \text { Characteristics of carpenter } \\
\text { cohort; values are number (\%) except } \\
\text { for age }\end{array}$} \\
\hline \multicolumn{2}{|l|}{ Characteristic } \\
\hline \multicolumn{2}{|l|}{ Gender } \\
\hline Male & $5110(99.5)$ \\
\hline Female & $15(0.29)$ \\
\hline Unknown & $12(0.23)$ \\
\hline \multicolumn{2}{|l|}{ Age in years* } \\
\hline Mean (range) & 32.7 \\
\hline Median & 31 \\
\hline Range & $18-71$ \\
\hline \multicolumn{2}{|c|}{ Hours worked by union status $t$} \\
\hline Apprentice & $3160230(33.8)$ \\
\hline Journeymen & $6047468(64.7)$ \\
\hline Missing & $138905(1.5)$ \\
\hline
\end{tabular}

\section{RESULTS}

\section{Active surveillance}

The cohort consisted of 5137 carpenters who worked for one of 20 participating contractors; these contractors hired a total of 9346603 carpenter hours from 1 September, 1999 through 30 September 2002. Characteristics of the cohort are presented in table 1 .

During 37 months of data collection, 783 injuries were reported to the project office; 586 carpenters (75\%) were interviewed. We were unable to locate 75 individuals, making the participation rate $83 \%$ among carpenters we were able to reach. Nail guns were involved in 80 (13.6\%) injuries.

The injuries are presented in table 2 by nature of injury and body region involved. Over half involved puncture wounds to the hand or fingers. We had information on lost time from work for 75 of the nail gun related injuries; of these $52 \%$ $(n=39)$ had lost time beyond the day of injury.

The mechanisms of these injuries are presented in table 3. Seventy six $(95 \%)$ of the injuries were the result of the carpenter being struck; nail guns were the single greatest cause of carpenters being struck, accounting for $23 \%$ of all struck by injuries. Of the five individuals with eye injuries, three were using no eye protection. Two were wearing safety glasses with side shields; one got debris over the top of his glasses as he worked overhead and the second had his glasses slide down his nose as he worked in the heat.

Although screw gun injuries were seen in drywall work, all nail gun injuries occurred in residential construction. To get a more accurate measure of risk, rates were calculated using only residential work hours (hours $=7739417$ ). The overall rate of injuries associated with nail guns was 2.1 per 200000 hours worked (95\% CI 1.7 to 2.6). Injuries were more common among apprentices with 35\% occurring in the first year of apprenticeship, $21 \%$ in the second year, $13 \%$ in the third year, and an additional $4 \%$ in the fourth year. The injury rate among apprentices was 3.7 per 200000 hours worked (95\% CI 2.7 to 4.9 ) compared to a rate of 1.2 among journeymen (95\% CI 0.80 to 1.7). All injuries were among male carpenters.

The type of nailing activity, determined from the surveillance descriptions, are presented by type of triggering mechanism on the tool in table 4 . Injuries with both contact trip and sequential trigger tools occurred most frequently while through nailing.

In table 5, factors contributing to the injuries are presented by type of triggering mechanism on the tool involved in the injury. It is of note that the categories are not mutually exclusive. Although based on small numbers, similar proportions of injuries involved use of the non-dominant hand, awkward 
Table 2 Injuries associated with nail guns among union residential carpenters by nature of injury and body region, 1999-2002

\begin{tabular}{|c|c|c|c|c|c|c|c|}
\hline \multirow[b]{2}{*}{ Body region } & \multicolumn{7}{|c|}{ Nature of injury } \\
\hline & $\begin{array}{l}\text { Puncture } \\
\text { wound }\end{array}$ & $\begin{array}{l}\text { Fracture/ } \\
\text { broken tooth }\end{array}$ & Contusion & Abrasion & $\begin{array}{l}\text { Sprain/ } \\
\text { strain }\end{array}$ & $\begin{array}{l}\text { Repetitive } \\
\text { motion }\end{array}$ & Total (\%) \\
\hline Hand/fingers & 46 & 4 & 2 & & & & $52(65)$ \\
\hline Forearm/wrist & 1 & & & & & 2 & $3(4)$ \\
\hline Foot/toes & 9 & 3 & 1 & & & & $13(16)$ \\
\hline Knee/thigh & 3 & & 1 & & & & $4(5)$ \\
\hline Back & & 1 & & & 1 & & $2(3)$ \\
\hline Eye & 1 & & & 4 & & & $4(5)$ \\
\hline Face (tooth) & & 1 & & & & & $1(1)$ \\
\hline Total (\%) & $60(75)$ & $9(11)$ & $4(5)$ & $4(5)$ & $1(1)$ & $2(3)$ & $80(100)$ \\
\hline
\end{tabular}

Table 3 Mechanism of nail gun injuries among union residential carpenters, 1999-2002

\begin{tabular}{|c|c|c|}
\hline Mechanism & Frequency (\%) & Descriptions \\
\hline Struck by/against & $76(95)$ & $\begin{array}{l}\text { Hit by nail from tool ( } n=70 \text {; } \\
\text { includes } 1 \text { eye injury) } \\
\text { Hit by debris from nail ( } n=4 \text {; } \\
\text { eye injuries) } \\
\text { Hit by gun ( } n=2 \text {; tool recoil } \\
\text { and dropped) }\end{array}$ \\
\hline Fall from height & $1(1)$ & $\begin{array}{l}\text { Leaning over to nail gutter } \\
\text { board from roof }\end{array}$ \\
\hline Repetitive activity & $2(3)$ & $\begin{array}{l}\text { Developed carpal tunnel } \\
\text { syndrome in dominant arm; } \\
\text { carpenter attributed to use of } \\
\text { framing nailer and } \\
\text { associated awkward wrist } \\
\text { postures. Forearm strain; } \\
\text { attributed to use of tool } \\
\text { overhead with difficult trigger } \\
\text { safety mechanism }\end{array}$ \\
\hline Overexertion & $1(1)$ & $\begin{array}{l}\text { Strained back when picked } \\
\text { up tool from ground }\end{array}$ \\
\hline
\end{tabular}

Table 4 Type of nailing activity associated with nail gun injuries by triggering mechanism among union residential carpenters, 1999-2002; values are frequency $(\%)$

\begin{tabular}{lll}
\hline & \multicolumn{2}{l}{ Type of trigger mechanism* } \\
\cline { 2 - 3 } Activity & $\begin{array}{l}\text { Contact trip } \\
\text { trigger }(n=53)\end{array}$ & $\begin{array}{l}\text { Sequential } \\
\text { trigger }(n=18)\end{array}$ \\
\hline $\begin{array}{l}\text { Through nailing (nailing two pieces } \\
\text { of wood together, such as joining } \\
2 \times 4 \text { 's or blocks in framing) }\end{array}$ & $12(60)$ \\
$\begin{array}{l}\text { Toe nailing (nailing at an } \\
\text { angle, such as in corners) }\end{array}$ & $5(9)$ & $3(17)$ \\
$\begin{array}{l}\text { Flat nailing (sheathing activities, } \\
\text { such as flooring or roofing) }\end{array}$ & $9(17)$ & $1(6)$ \\
$\begin{array}{l}\text { Not nailingt } \\
\text { Could not code based on } \\
\text { information collected }\end{array}$ & $2(4)$ & $1(6)$ \\
\hline $\begin{array}{l}\text { *Triggering mechanism unknown for nine injuries; including injuries } \\
\text { from fall, overexertion, repetitive motion ( } n=4) .\end{array}$ \\
$\begin{array}{l}\text { tRepresent gun dropped from above and contact with nose piece of } \\
\text { gun being carried/moved. }\end{array}$
\end{tabular}

postures, ricochets, penetration of the nailing surface, and lack of eye protection for both trigger types, while contact trip triggers were associated with more rapid, double fires. Ricochets occurred due to hitting knots in wood materials, metal truss components, other nails, and from dense laminated materials. Awkward postures often occurred while working in rafters or trusses. While not always the sole contributing factor, in 36
Table 5 Factors contributing to nail gun injuries * among union residential carpenters by trigger mechanism of tool, 1999-2002; values are number (\%)

\begin{tabular}{|c|c|c|}
\hline \multirow[b]{2}{*}{ Contributing factor } & \multicolumn{2}{|c|}{ Type of trigger mechanism $\dagger$} \\
\hline & $\begin{array}{l}\text { Contact trip } \\
\text { trigger ( } n=53)\end{array}$ & $\begin{array}{l}\text { Sequential } \\
\text { trigger }(n=18)\end{array}$ \\
\hline $\begin{array}{l}\text { Use of non-dominant hand to } \\
\text { handle tool }\end{array}$ & $6(11)$ & $2(11)$ \\
\hline $\begin{array}{l}\text { Placement of hand not holding } \\
\text { tool/body (bracing materials, } \\
\text { shooting towards self) }\end{array}$ & $18(33)$ & $9(50)$ \\
\hline $\begin{array}{l}\text { Awkward posture (work in rafters, } \\
\text { leaning over, overhead, shooting } \\
\text { back towards self) }\end{array}$ & $8(15)$ & $3(17)$ \\
\hline $\begin{array}{l}\text { Nail ricocheted (knot, laminated } \\
\text { beams, metal truss components) }\end{array}$ & $12(23)$ & $6(33)$ \\
\hline $\begin{array}{l}\text { Rapid double fire, uncontrolled, } \\
\text { misfire }\end{array}$ & $17(32)$ & $1(6)$ \\
\hline Penetration of wood surface & $11(21)$ & $4(22)$ \\
\hline Projectile nail & $9(17)$ & 0 \\
\hline By-passed safety mechanism & $19(36)$ & 0 \\
\hline Lack of eye protection & $2(4)$ & $1(6)$ \\
\hline
\end{tabular}

cases $(68 \%$ of the injuries from guns with contact trips triggers and $45 \%$ of injuries overall) the injury would likely have been prevented by a sequential trigger.

\section{Supplementary survey from apprentices}

Questionnaires were received from 165 apprentices. Seventy three percent $(n=121)$ had been in the union for less than one year; $66 \%(n=109)$ had more than a year of carpentry experience and $16 \%(n=26)$ had more than five years' experience. Training in the use of these tools is presented in table 6 and ranged from being told "don't shoot yourself" to formal programs. The most common training was "hands on", followed by lectures, tool box talks or safety meetings, and video instruction. Forty carpenters $(24 \%)$ reported that they had no training in tool use. We did not examine the relationship between training and injury since we had no information on time sequence.

Reports of the proportion of nail gun use by apprentices on residential sites are presented in fig 2 . On over half the sites, apprentices reported doing the majority of nailing with guns.

Fifty four apprentices $(33 \%)$ reported a work related nail gun injury; 35 occurring in the last year. Nineteen individuals $(11.5 \%)$ had experienced more than one injury. The patterns they reported were similar to those collected through the active surveillance. The apprentice was using the gun at the time of injury in $84 \%$ of the cases.

All injuries were associated with framing nailers and all occurred while framing or sheathing. Eleven injuries occurred 


\begin{tabular}{|c|c|}
\hline \multicolumn{2}{|c|}{$\begin{array}{l}\text { Table } 6 \text { Nail gun training received } \\
\text { by apprentices, carpenter apprentice } \\
\text { survey }\end{array}$} \\
\hline Type of training* & $\begin{array}{l}\text { Frequency } \\
(\%)\end{array}$ \\
\hline Read pamphlet & $15(9.1)$ \\
\hline Lecture & $52(31.5)$ \\
\hline Tool box talk/safety meeting & 28 (17.0) \\
\hline "Hands on" training & $80(48.5)$ \\
\hline Video & 22 (13.3) \\
\hline $\begin{array}{l}\text { Other (foreman explained, dad } \\
\text { taught, tested on pamphlet, told } \\
\text { "don't shoot yourself," } \\
\text { company training and test) }\end{array}$ & $10(6.1)$ \\
\hline None & 40 (24.3) \\
\hline \multicolumn{2}{|c|}{$\begin{array}{l}\text { *Categories are not mutually exclusive; some } \\
\text { carpenters had training through more than one } \\
\text { method. }\end{array}$} \\
\hline
\end{tabular}

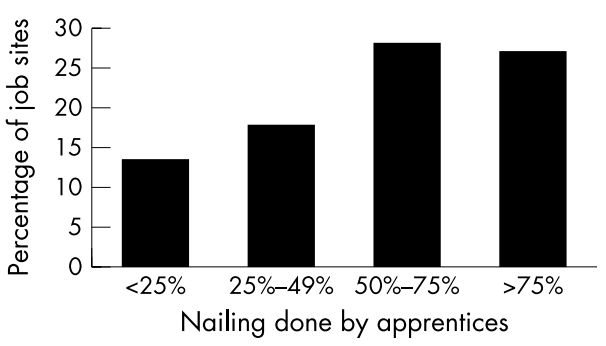

Figure 2 Proportion of nailing with guns done by apprentices, apprentice survey.

while the apprentice was "bounce nailing". Thirty five percent of the apprentices reported working for contractors who used sequential triggers; these triggers were used on the tools in only three cases when the carpenter was injured ( $6 \%$ of the injuries).

The circumstances surrounding these injuries were described in 51 cases and included 15 (29\%) accidental misfires, three accidental contacts with the gun, and 12 gun recoils resulting in double fire. In 19 cases $(37 \%)$ there was penetration of the board being nailed due to splintering, deflection from a knot or another nail, or misplacement of the tool. In over half $(53 \% ; n=27)$ of the injuries there was a flying or airborne nail. As in the surveillance analyses, the categories are not mutually exclusive.

\section{DISCUSSION}

\section{Strengths and contributions of the study}

Through this report the utility of active injury surveillance among a group of union carpenters is demonstrated. The combination of data elements allowed both the estimation of injury rates and examination of specific circumstances associated with each injury using information collected from injured carpenters by their peers. The availability of the text descriptions allowed exploration of issues that had not been anticipated when the surveillance tool was designed. Participation by injured workers was high, likely due to the interviewers being carpenters with knowledge of the work environment and tools.

The information allowing identification of hours worked by apprentices and journeymen was very revealing. While the overall injury rate was identical to that reported by Baggs et $a l_{1}^{7}$ injury rates over three times higher among apprentices than among journeymen were documented, likely related to more hours of exposure as well as inexperience. Recognizing we did not capture all injuries among the cohort, our frequency and rate estimates are likely conservative. They are still higher than reported for construction workers in Ohio and North Carolina. ${ }^{14}$ This is not surprising since rate calculations were for all trades involved in homebuilding in North Carolina and all union carpenters in Ohio; both groups included workers who did not use these tools and were not at risk, resulting in lower rates. More similar rates were observed when analyses were restricted to carpenters in North Carolina and residential construction in Ohio.

The majority of injuries involved puncture wounds to the hand or fingers, but should not be assumed to be insignificant injuries. Half of these men lost time from work and one injury resulted in a lengthy hospitalization for treatment of a wound infection.

Many of these injuries were felt to be related to the use of a contact trip trigger. While the triggering mechanism was not always the only contributing factor, in all likelihood the injury would not have occurred with a sequential safety feature. As far back as 1987, recommendations were made to develop a triggering mechanism that would allow the discharge of only one nail, rather than rapid fire nailing..$^{15}$ While these tools are now available, they are not widely used. Lastly, these data are from the perspective of carpenters-both the injured workers and investigators-with knowledge of their tasks and tools, but also the organizational structure under which they work. While some might view this as a limitation, we see this as a significant strength resulting in knowledge based, practical recommendations.

\section{Limitations}

In addition to voluntary participation by injured workers, the surveillance program involved voluntary reporting of injuries by contractors, and ascertainment of injuries was not complete. For example, one drywall contractor elected to screen all injured workers before reporting. Our recommendations are based on the universe of injuries investigated and we cannot guarantee they are entirely representative. However, the overall injury rates are higher than reported by the Bureau of Labor Statistics, ${ }^{16}$ and the rates for nail gun injuries are very similar to those estimated by others, ${ }^{67}{ }^{14}$ which is reassuring.

Data collection was limited to individuals who were injured providing no information on actual time spent using the tools or doing different types of nailing. Due to the manner in which our surveillance tool was designed, carpenters with repetitive motion complaints or sprains/strains were not asked what type of triggering mechanisms they had used, although few injuries of this nature were seen. Interviews were conducted shortly after the injuries occurred making it difficult to assess severity, particularly long term sequelae.

\section{IMPLICATIONS FOR PREVENTION}

These data provide evidence that training, engineering modifications, and policy changes in the workplace and manufacturing arena are all appropriate targets for prevention of injuries associated with nail guns. One action, without attention to the others, will not address the variety of issues that appear to be involved. Regardless of whether the high injury rates among apprentices are related to more exposure to the tools or inexperience, these workers warrant targeted prevention efforts. The use of these tools cannot be assumed to be an unskilled task; training should not be limited to how to use and maintain the tools. Workers need to know how to safely position the tool and their bodies to prevent injury to themselves and co- workers. They should be aware of circumstances that are associated with inadvertent penetrations or ricochets including knots in wood, presence of other nails or metal truss components, and nailing into some of the newer, dense manufactured materials such as laminated beams and joists. As with any power tool, malfunctioning tools should be removed from service immediately. Training and workplace policy need to address the use of appropriate eye protection when using these tools. ${ }^{17} 18$ 
The findings support the move to sequential triggers to decrease acute injury rates. Workers do not typically purchase these tools; the contractors who do, must be involved in this effort. Sequential triggers come on some, or can be installed on, new tools as well as being retrofitted on older tools, often at no cost. However, the sequential trigger is still not the industry standard. Leverage from workers' compensation insurance carriers could influence practice in the field and growing litigation from injured workers against the industry may force change. ${ }^{19}$ Contact trip tools allow rapid fire "bounce nailing", a reason cited for their preference in this fast paced industry. We are unaware of any reports evaluating the accuracy of rapid fire nailing. If nails do not hit the target, construction quality suffers and unnecessary numbers of nails may be used, offsetting productivity gains from rapid fire contact trip tools. Contractors have also voiced concern over raising risks for repetitive trauma by requiring the use of sequential triggering tools and this issue should be evaluated. However, we saw few injuries of a cumulative nature compared to acute injuries making us question whether this fear is well founded.

There are other areas where innovative engineering could help prevent injury regardless of the triggering mechanism. Design features of the nose piece could be improved. Because the tools discharge if any part of the nose piece is depressed, a worker can shoot over the intended surface. The use of a laser to clearly identify the target might improve placement of the nose contact. Creation of "aggressive" nose pieces have been described in trade journals. ${ }^{20}$ To do this, the worker files the ends of the nose piece to create a rough contact that will grab materials and prevent slipping. This aggressive nose piece would be a hindrance in rapid sheathing activities, pointing to the utility, perhaps, of interchangeable nose pieces that could easily be changed.

From these data there appear to be some situations, or tasks, that are better suited for the use of a hammer and nails, for example, when the individual has to be in awkward positions where the heavy gun and trailing hose make proper placement difficult and may magnify hazards for falling. Nailing in trusses is such an example.

There are also situations where the use of a nail gun really helps; rapid, secure placement of a nail can prevent creeping of materials and the tools speed up productivity for sheathing, particularly. The majority of injuries in these carpenters were associated with through nailing tasks, such as nailing studs or blocks, trusses or joists, as opposed to flat nailing used for sheathing activities. This provides some indication that contact trip tools might be safely used for flat nailing tasks such as sheathing or roofing. However, from an organizational standpoint, it is questionable whether tools would truly be designated for certain tasks based on the triggering mechanism; and there are dangers associated with contact trip tools, including carrying them with a finger on the trigger, that have nothing to do with specific nailing tasks.

Engineering changes and training programs should be developed and evaluated based on ongoing surveillance efforts. Both need to keep pace with materials development, such as the increasing use of very dense pre-manufactured beams which are more difficult to penetrate than wood. Carpenters in the field and the contractors, who hire them and are responsible for their safety, need to be involved in these processes.

\section{ACKNOWLEDGEMENTS}

This work was supported by a grant from the National Institute for Occupational Safety and Health (NIOSH) (ROl OH103809). Its contents are solely the responsibility of the authors and do not necessarily represent the official views of NIOSH. The authors acknowledge Terry Nelson, Executive Secretary-Treasurer of the Carpenters District Council of Greater St Louis and Vicinity; Patrick Sullivan, Executive Vice President of the Home Builders Association of Greater St Louis; and John S Gaal, Coordinator, Saint Louis Carpenters Joint

\section{Key points}

- Nail guns are responsible for an estimated $14 \%$ of injuries among residential carpenters.

- Nail guns are the single greatest cause of struck by injuries among residential carpenters, responsible for $>20 \%$ of these injuries.

- Injury rates are over three times higher among apprentice carpenters than journeymen, likely due to greater exposure to these tools and inexperience.

- Over $65 \%$ of injuries associated with contact trip guns could likely be prevented by sequential triggers.

- Prevention should involve training, engineering and policy changes involving carpenters and contractors, and these efforts should be evaluated and informed by ongoing injury surveillance.

Apprenticeship Committee (CJAC) for their support, recruitment of contractors and guidance. We also wish to thank Ron Laudel, Benefits Plan Administrator, Carpenters' District Council of Greater St. Louis for providing regular updates of the cohort and hours worked, and Mark Fuchs, Instructor (CJAC), for coordinating surveys with apprentices and providing input into possible prevention strategies. Lastly, we thank all participating contractors, and their staff, who reported injuries to the project office.

\section{Authors' affiliations}

H J Lipscomb, J M Dement, L Li, Division of Occupational and Environmental Medicine, Department of Community and Family Medicine, Duke University Medical Center, Durham, North Carolina J Nolan, D Patterson, Carpenters District Council of Greater St Louis, St Louis, Missouri

\section{REFERENCES}

1 Bruno JR, Levin LM, Stanton DC. Pneumatic nail gun injury to the maxillofacial region: case report. J Trauma 1998;45:410-12.

2 Albericco G, Bucci I, Ciarelli F, et al. An unusual case of nail gun injury: penetrating neck wound with nail retention in the right pleural cavity. J Trauma 1997;43:153-6.

3 Kizer KW, Boone HA, Heneveld E, et al. Nail gun injury to the heart. J Trauma 1995;38:382-3.

4 Kenny N, O'Donaghue D, Haines J. Nail gun injuries. J Trauma 1993;35:943-5.

5 Wu WQ, Tham CF, Oon CL. Cranio-cerebral injuries from nail-gun used in the construction industry. Surg Neurol 1975;3:83-8.

6 Baggs J, Cohen M, Kalat J, et al. Pneumatic nailer ("nail gun") injuries in Washington State, 1990-1998, Safety and Health Assessment and Washington State, 1990-1998, Safety and Health Assessment and
Research for Prevention (SHARP) Program. Olympia, WA: Washington State Department of Labor and Industries, Technical report number 59-1-1999.

7 Baggs J, Cohen M, Kalat J, et al. Pneumatic nailer injuries: a report on Washington State 1990-1998. Professional Safety Magazine January 2001.

8 Webb DP, Ramsey JJ, Dignan RJ, et al. Penetrating injury to the heart requiring cardiopulmonary bypass: a case study. Journal of Extra-corporeal Technology 2001;33:249-51.

9 Jithoo R, Govender ST, Nathoo N. Penetrating nail gun injury of the head and chest with incidental pericallosal artery anerysm. S Afr Med J 2001:91:316-17.

10 Wang MJ, Chen IS, Tsai SK. Nail gun penetrating injury of the left ventricle and descending aorta. Circulation 1999;100:e18-19.

11 Haenszel W, Loveland D, Sirken $M$. Lung-cancer mortality as related to residence and smoking histories. J Natl Cancer Inst 1962; appendix C: 1000 .

12 SAS Institute, Inc. The SAS system, version 8.0. Cary, NC: SAS Institute, Inc, 1999.

13 Microsoft. ACCESS 97. Version 4.0. Seattle, WA: Microsoft, 1997.

14 Dement JM, Lipscomb HJ, Li L, et al. Surveillance of nail gun injuries among construction workers. Appl Occup Environ Hyg (in press, May 2003).

15 Nobel JL, Wing PC. Pneumatic nail gun injuries to the knee. Clin Orthop 1987:217:228-9.

16 US Department of Labor, Bureau of Labor Statistics. Industry at a glance, construction. Available at: wysiwyg://24//http:// www.bls.gov/iag/iag.construction. html (25 April 2002).

17 Lipscomb HJ, Dement JM, McDougall V, et al. Work-related eye injuries among union carpenters. Appl Occup Environ Hyg 1999; 14:665-76.

18 Lipscomb HJ. Effectiveness of Interventions to prevent work-related eye injuries. Am J Prev Med 2000;18(4S):27-32.

19 Charmas SE. Nailing down the nail gun case (safe at home and at work). Trial 1996;32(8):30-4.

20 Arnold R, Guertin M. Framing with nail guns. Fine Homebuilding June/July 1999:74-80. 